\title{
Norms for Eating Disorder Examination Questionnaire (EDE-Q) among Secondary School Students in Kuala Lumpur, Malaysia.
}

\author{
Musa $\mathrm{R}^{\mathrm{a}}$, Bujang $M \mathrm{~A}^{\mathrm{b}}$, Haniff $\mathrm{J}^{\mathrm{c}}$, Mohamad $N \mathrm{~A}^{\mathrm{d}}$, Omar $\mathrm{K}^{\mathrm{d}}$, Radeef $A \mathrm{~S}^{\mathrm{a}}$ \\ ${ }^{a}$ Department of Psychiatry, Kulliyyah of Medicine, International Islamic University Malaysia, Jalan Hospital, \\ 25150 Kuantan, Pahang, Malaysia \\ ${ }^{b}$ Clinical Research Centre, Ministry of Health Malaysia, Jalan Pahang 50586, Kuala Lumpur. \\ 'Clinical Epidemiology Unit, Clinical Research Centre, Ministry of Health Malaysia, Jalan Pahang 50586, \\ Kuala Lumpur. \\ ${ }^{d}$ Faculty of Medicine, UKM Medical Centre, Bandar Tun Razak, 56000 Cheras, Kuala Lumpur
}

\begin{abstract}
Introduction: The Eating Disorder Examination Questionnaire (EDE-Q) has been widely used as a tool to detect eating disorders. We aimed to identify the EDE-Q normative data among secondary school students in Kuala Lumpur, Malaysia. Methods: This is a cross-sectional study involving four secondary schools in an urban area. The respondents of secondary school students were selected using stratified sampling. Results: There were 298 teenagers 12 to 17 years of age who participated in the study. The EDE-Q mean scores \pm standard deviation was $1.27 \pm 1.08$ for the total score (Global Score), $0.78 \pm 0.95$ for Restraint Domain, 1.02 \pm 1.03 for Eating Concern, $1.76 \pm 1.55$ for Shape Concern and $1.54 \pm 1.43$ for Weight Concern. Conclusion: Mean values obtained from this study were relatively lower when compared to western populations. Shape Concern and Weight Concern had higher scores compared to the other domains. These values are useful for EDE-Q interpretation in Malaysia.
\end{abstract}

Keywords: EDE-Q, normative data, Malaysian, secondary school students, eating disorders.

\section{INTRODUCTION}

The second and third Malaysian National Health and Morbidity Surveys in 1996 and 2006 respectively revealed a three-fold increase in obesity prevalence among adults, surging from $4.4 \%$ to $14 \%$ over the 10 -year period. ${ }^{1}$ It has been demonstrated that onefifth of Malaysian primary school children were overweight in 2006. ${ }^{2}$ Therefore one of the strategies to address this issue is to establish a reliable scale with its normative data. The scale will have the ability to measure Malaysian eating habits, hence it will be able to detect the many types of eating disorders.

The Eating Disorder Examination (EDE) interview is regarded as the "gold standard" tool for assessment of abnormal eating habits. ${ }^{3}$ The EDE is quite comprehensive as compared to other scales

Corresponding author:

Prof. Dr. Ramli Musa

Department of Psychiatry,

Kulliyyah of Medicine,

International Islamic University Malaysia,

Jalan Hospital, 25150 Kuantan, Pahang,

Malaysia

Tel: $+609-5716400$

Fax: $+609-5133615$

Email:ramlidr@yahoo.com/drramli@iium.edu.my which were designed to measure abnormal eating attitudes. ${ }^{4}$ Other scales with the same purpose include the Eating Attitudes Test $(\text { EAT-26) })^{5}$, the Eating Disorder Inventory (EDI-2) ${ }^{6}$, the Three Factors Eating Questionnaire (TFEQ) ${ }^{7}$ and the SCOFF questionnaire $^{8}$. The Eating Disorder Examination Questionnaire (EDE-Q) is derived from the Eating Disorder Examination interview (EDE). Even though it is a self-report questionnaire, the EDE-Q performs similarly to the EDE in the detection of eating disorder cases, although slight differences have been observed due to self-reporting bias. ${ }^{9}$

The EDE-Q has been translated into the Malaysian language. Based on its validation effort, the Malaysian language version had good psychometric values. It had good internal consistency with global Cronbach's alpha value of 0.88 . Analysis of validity, the Principle Component Factor produced four domains with unforced Varimax rotation. ${ }^{10}$

In order to incorporate EDE-Q as a useful tool to screen eating disorders in Malaysia, we need to establish the normative data for the local population. The population normative data for certain parameters can be culturally related especially in the aspect of eating behaviour and attitude. Malaysian eating behaviour and attitude may be different to other regions especially western. 
Results of this study would provide an overview on Malaysia normative values based on the validated EDE-Q.

\section{METHODS}

This is a cross-sectional study, involving four secondary schools in Kuala Lumpur. The study obtained the approval from Department of Education before it was conducted. The participants were secondary school children.

The inclusion criteria were those aged between 12 and 17 years old and consented by their parents. The selection of the schools was based on the consideration that the students' composition is multiracial and not predominantly by any specific ethnic groups. From the total of 54 government operated schools, 28 schools were excluded due to race preponderance to 1 ethnic group. The random sampling was done among 26 schools and the named 4 schools were selected in this study.

The schools were SMK Taman Maluri, SMK Puteri Titiwangsa, SMK Seri Titiwangsa and SMK Setapak Indah. The study protocol was approved by the Ethics Committee of Clinical Research Centre Kuala Lumpur. From a total of 648 students in these schools, 350 students were initially selected by random sampling.

On the second phase of recruitment, the potential participants were further selected using stratified quota sampling based on race, gender and academic performance to represent Malaysian population. From 350 selected students, 49 students failed to get parental consents and 3 students did not complete their forms. Hence our analysis is based on 298 students.

The administration of the EDE-Q was conducted by researchers with the help of 2 trained research assistants. Participants were briefly explained the purpose of the study and the EDE-Q scale.

\section{RESULTS}

There were 298 secondary school students who participated in the study. The majority were Malays and aged from 14 to 15 years old (Table 1 ).
Table 1: Distribution of sociodemographic data by gender

\begin{tabular}{|c|c|c|c|c|}
\hline & $\mathrm{N}=298(\%)$ & $\begin{array}{c}\text { Mean of } \\
\text { EDE-Q } \\
\text { total } \\
\text { scores }\end{array}$ & SD & $\begin{array}{c}\text { p-value } \\
\text { (Chi- } \\
\text { square) }\end{array}$ \\
\hline \multicolumn{5}{|l|}{ Age } \\
\hline $12-13$ & 21(7.0) & & & \\
\hline $14-15$ & $173(58.0)$ & & & \\
\hline $16-17$ & 104(34.9) & & & \\
\hline \multicolumn{5}{|l|}{ Race } \\
\hline Malay & $189(63.4)$ & 10.7 & 8.1 & $<0.001$ \\
\hline Chinese & $84(28.2)$ & 7.9 & 8.4 & \\
\hline $\begin{array}{l}\text { Indian \& } \\
\text { others }\end{array}$ & $25(8.4)$ & 13.7 & 7.1 & \\
\hline \multicolumn{5}{|l|}{ Gender } \\
\hline \multirow{2}{*}{$\begin{array}{l}\text { Male } \\
\text { Female }\end{array}$} & $141(47.3)$ & 7.9 & 7.4 & \multirow[t]{2}{*}{$<0.001$} \\
\hline & $157(52.7)$ & 11.9 & 8.5 & \\
\hline \multicolumn{5}{|l|}{$\begin{array}{l}\text { Academic } \\
\text { achievement }\end{array}$} \\
\hline Excellent & $36(12.1)$ & 19.2 & 9.4 & \multirow{3}{*}{0.373} \\
\hline Average & $225(75.5)$ & 10.1 & 9.5 & \\
\hline Poor & $37(12.4)$ & 12.8 & 10.2 & \\
\hline \multicolumn{5}{|l|}{ Parents' } \\
\hline \multicolumn{5}{|l|}{ Income } \\
\hline < RM 1000 & $75(25.2)$ & 11.5 & 9.1 & 0.100 \\
\hline \multirow{2}{*}{$\begin{array}{l}\text { RM 1001- } \\
5000\end{array}$} & 117 (39.3) & 11.4 & 8.1 & \\
\hline & $30(10.1)$ & 11.0 & 7.4 & \\
\hline > RM 5000 & $76(25.5)$ & & & \\
\hline $\begin{array}{l}\text { Don't } \\
\text { know }\end{array}$ & & & & \\
\hline
\end{tabular}

Analysis of the data for both genders revealed the global score and domain scores for EDEQ are as follows; $1.27 \pm 1.08$ for Global, $0.78 \pm 0.95$ for Restrain, $1.02 \pm 1.03$ for Eating Concern, $1.76 \pm 1.55$ for Shape Concern and $1.54 \pm 1.43$ for Weight Concern. Further analysis was based on gender to see for any differences. 
Table 2: Eating Disorder Examination Questionnaire 6.0 (EDE-Q) descriptive data and percentile ranks global and subscale scores ( $N=141)$ for male participants.

\begin{tabular}{|c|c|c|c|c|c|c|}
\hline Mean (SD) & & $\begin{array}{c}\text { Global } \\
\text { Score } \\
0.95(0.95)\end{array}$ & $\begin{array}{c}\text { Restraint } \\
0.75(1.00)\end{array}$ & $\begin{array}{c}\text { Eating } \\
\text { Concern } \\
0.76(0.85)\end{array}$ & $\begin{array}{c}\text { Shape } \\
\text { Concern } \\
1.19(1.34)\end{array}$ & $\begin{array}{c}\text { Weight } \\
\text { Concern } \\
1.11(1.22)\end{array}$ \\
\hline \multirow[t]{20}{*}{ Percentiles } & 5 & 0.03 & - & - & - & - \\
\hline & 10 & 0.06 & - & - & - & - \\
\hline & 15 & 0.10 & - & - & - & - \\
\hline & 20 & 0.15 & - & - & 0.13 & 0.20 \\
\hline & 25 & 0.19 & - & - & 0.13 & 0.20 \\
\hline & 30 & 0.25 & - & 0.20 & 0.25 & 0.20 \\
\hline & 35 & 0.28 & - & 0.20 & 0.38 & 0.40 \\
\hline & 40 & 0.31 & - & 0.20 & 0.48 & 0.40 \\
\hline & 45 & 0.49 & 0.20 & 0.40 & 0.63 & 0.60 \\
\hline & 50 & 0.74 & 0.20 & 0.40 & 0.63 & 0.60 \\
\hline & 55 & 0.87 & 0.40 & 0.60 & 0.75 & 1.00 \\
\hline & 60 & 0.97 & 0.60 & 0.80 & 0.88 & 1.20 \\
\hline & 65 & 1.15 & 0.66 & 0.86 & 1.25 & 1.20 \\
\hline & 70 & 1.30 & 1.20 & 1.20 & 1.43 & 1.40 \\
\hline & 75 & 1.48 & 1.20 & 1.20 & 1.88 & 1.60 \\
\hline & 80 & 1.66 & 1.40 & 1.40 & 2.13 & 1.80 \\
\hline & 85 & 1.94 & 1.60 & 1.60 & 2.80 & 2.40 \\
\hline & 90 & 2.37 & 2.40 & 2.00 & 3.35 & 3.00 \\
\hline & 95 & 2.96 & 3.00 & 2.40 & 3.75 & 3.58 \\
\hline & 99 & 4.31 & 4.15 & 3.72 & 6.00 & 5.50 \\
\hline
\end{tabular}

Table 2 shows that the mean \pm standard deviation for total and domain scores for male participants are as follows; $0.95 \pm 0.95$ for Global, $0.75 \pm 1.00$ for Restraint, $0.76 \pm 0.85$ for Eating Concern, $1.19 \pm$ 1.34 for Shape Concern and $1.11 \pm 1.22$ for Weight Concern. The standard deviations are between 0.95 and 1.34 which were relatively small. Shape Concern and Weight Concern had higher mean scores as compared to the other domains.

The Global Score is the total score for all four domains (Restrain, Eating Concern, Shape Concern and Weight Concern). Restrain score is referring to the total scores for all items related to the restrain behaviours. Eating Concern score is the total score of all items related to eating restriction. Shape Concern score is the total score of items designed to measure concern on body shape and the Weight Concern score is the total score of items concerning overweight worries.

Table 3 shows the mean score for female participants. The table shows $1.56 \pm 1.12$ is the mean score for Global, $0.81 \pm 0.91$ for Restraint, $1.25 \pm 1.11$ for Eating Concern, $2.27 \pm 1.54$ for Shape Concern and $1.56 \pm 1.12$ for Weight Concern. Again Shape Concern and Weight Concern had higher scores when compared to the other domains 
Table 3: Eating Disorder Examination Questionnaire 6.0 (EDE-Q) descriptive data and percentile ranks global and subscale scores $(N=157)$ for female participants.

\begin{tabular}{llcrrrr}
\hline & & $\begin{array}{c}\text { Global } \\
\text { Score }\end{array}$ & Restraint & $\begin{array}{c}\text { Eating } \\
\text { Concern }\end{array}$ & $\begin{array}{c}\text { Shape } \\
\text { Concern }\end{array}$ & $\begin{array}{c}\text { Weight } \\
\text { Concern }\end{array}$ \\
\hline Mean (SD) & & $1.56(1.12)$ & $0.81(0.91)$ & $1.25(1.11)$ & $2.27(1.54)$ & $1.56(1.12)$ \\
Percentiles & 5 & 0.19 & - & - & 0.24 & - \\
& 10 & 0.38 & - & - & 0.48 & 0.20 \\
& 15 & 0.48 & - & .14 & 0.63 & 0.40 \\
& 20 & 0.55 & - & 0.40 & 0.95 & 0.60 \\
& 25 & 0.69 & 0.20 & 0.40 & 1.13 & 0.60 \\
& 30 & 0.78 & 0.20 & 0.60 & 1.13 & 0.80 \\
& 35 & 0.89 & 0.40 & 0.60 & 1.38 & 0.86 \\
& 40 & 0.99 & 0.40 & 0.80 & 1.50 & 1.20 \\
& 45 & 1.04 & 0.40 & 0.80 & 1.63 & 1.40 \\
50 & 1.19 & 0.60 & 1.00 & 2.00 & 1.60 \\
& 55 & 1.43 & 0.60 & 1.20 & 2.36 & 1.80 \\
60 & 1.54 & 0.60 & 1.20 & 2.63 & 2.00 \\
65 & 1.79 & 0.80 & 1.40 & 2.75 & 2.40 \\
70 & 2.08 & 0.80 & 1.60 & 3.00 & 2.72 \\
75 & 2.38 & 1.20 & 1.80 & 3.25 & 3.00 \\
80 & 2.79 & 1.40 & 2.20 & 3.68 & 3.20 \\
85 & 3.02 & 1.60 & 2.40 & 4.25 & 3.86 \\
90 & 3.24 & 2.40 & 2.64 & 4.75 & 4.20 \\
95 & 3.60 & 3.00 & 3.60 & 5.13 & 4.62 \\
99 & 4.48 & 3.60 & 5.25 & 6.00 & 6.00 \\
\hline
\end{tabular}

\section{DISCUSSION}

Our study in the past was mainly aimed to look at the translation and validation aspects of EDE-Q. The results in this study showed that EDE-Q Malaysian version has good psychometric properties. The translated EDE-Q Malaysian version had very good internal consistency with global Cronbach's alpha value of 0.879 . For construct validity, majority of the items managed to produce the value of 0.4 and more for confirmatory factor analysis with four unforced distinct factors identified. ${ }^{10}$

The results of validity were concluded to be derived from enough samples for analysis of exploratory factor analysis. However in order to interpret the data, we need to establish the normative values within our local population. As we know the eating values are generally different from one population to the other. This is more pertinent when we want to compare eating attitudes between Asian and western populations.

To our knowledge, this is the first study to present normative EDE-Q data for Malaysian population and this study specifically focuses on secondary school students. It is important in deriving the normative scores as a reference for future research with regards to eating disorder particularly in Malaysia. The preliminary data is not only useful to make a comparison among countries in Asia, it is also useful to the future studies and researchers could compare the values among different age groups in the same population. Compared to past studies by Oyvind et al and Kristine et al, the normative scores for Malaysian secondary school students that we have derived from this study are relatively low. ${ }^{11,12}$ The difference between our study and the 2 cited studies is the age groups. The 2 cited studies were done among young adult women and undergraduates. Many studies in the past were just focusing on a single gender. Since this study was aimed to determine the normative scores for secondary school students in Malaysia, we recruited both genders as our sample.

Generally our population has lower global EDE-Q score $(1.27 \pm 1.08)$ as compared to other population such as Norway $(1.42 \pm 1.07)^{12}$, England $(1.55 \pm 1.25)$ 13 , Australia $(1.52 \pm 1.25)^{14}$ and America $(1.74 \pm 1.3)$ 15 . The contribution to the lower score may be due to the age difference. Our population is relatively younger to other cited populations. Studies in other countries as mentioned above were mainly conducted between ages 18 to 22 years old. Based on the mean scores and highest scores, we found there is a common finding in our population as compared to others. We found there is a common pattern of the scores between all 4 domains. We found that the scores for shape and weight concern are generally higher than other domains. ${ }^{11,12,13}$ In comparison with a Spanish study which was conducted among male and female adolescents of 
the same age range as ours, our participants had lower mean scores for all domains. ${ }^{16}$ These differences are observable for both genders. When we make a comparison between female and male participants, our female participants were found to have higher means for total and other domains. The trend that females scored higher means is also noticeable in various studies in the past. ${ }^{13,14,16}$

This study has some limitations. The selection of schools was not on ideal sampling. However we have a valid reason for this type of selection. As mentioned in the methodology, the selection of the schools was based on the consideration that the students' composition is multiracial and not predominantly specific to any ethnic groups. This is to ensure the sample would represent the true Malaysian population. Nevertheless we found that the characteristics of the participants are homogeneous and still represent the actual Malaysian population on the aspect of racial and gender distributions. Therefore the selection of stratified random sampling could be suitable for this type of study. The small bias in the sampling is rather justifiable as we notice the distribution of respondents based on their race and gender is still representing the Malaysian population. These four schools are daily ordinary schools and situated in urban area.

Due to fact that location of the schools is only in urban area, the results in this study may not be able to infer to the rural populations in Malaysia. Other limitation is the number of participants in this study is rather small. For future study, we recommend researchers to have bigger sample size and also to include biological parameters such as body mass index (BMI) and waist circumference. Therefore, the association between the BMI and the EDE-Q domains can be further studied. In conclusion, we attempted to establish the normative scores for EDE -Q among Malaysian secondary school children. This may serve as reference scores of normative sample of teenagers in Malaysia. The scores are considered as acceptable due to small standard deviations.

\section{REFERENCES}

1. Institute for Public Health (IPH). The National Health \& Morbidity Survey 2006 (NHMS III) 2008. Kuala Lumpur: Ministry of Health. ISBN: 9789833887293.

2. Naidu BM, Mahmud SZ, Ambak R, Sallehuddin SM, Mutalip HA, Saari R, Hamid HAA. Overweight among primary school-age children in Malaysia. Asia Pac J Clin Nutr. 2013;22(3):408-415.

3. Garner DM. Measurement of eating disorder psychopathology. In: Brownell KD, Fairburn CG, Editors. Eating Disorders and Obesity: A Comprehensive Handbook. New York: Guilford Press. 1995:117-121.

4. Fairburn CG, Beglin SJ. Assessment of eating disorders: Interview or self-report questionnaire? Int J Eat Disord. 1994;16:363- 370.
5. Garner DM, Olmsted MP, Bohr Y, Garfinkel PE. The Eating Attitudes Test: Psychometric features and clinical correlates. Psychological Medicine. 1982; 12:871-878.

6. Garner DM, Olmsted MP, Polivy J. Development and validation of a multidimensional Eating Disorder Inventory for anorexia nervosa and bulimia. Int J Eat Disord. 1983;2:15-34.

7. Yeomans MR, Tovey HM, Tinley EM, Haynes CJ. Effects of manipulated palatability on appetite depend on restraint and disinhibition scores from the Three-Factor Eating Questionnaire. Int J Obesity. 2004;28(1):144-151.

8. Fairburn CG, Cooper Z. The eating disorder examination. In: Fairburn CG, Wilson GT, Editors. Binge Eating: Nature, Assessment and Treatment. 12th ed. New York: Guilford Press. 1993; 317-360.

9. Fairburn CG, Beglin SJ. Assessment of eating disorders: interview or self-report questionnaire?. International Journal of Eating Disorders. 1994;16:363-370.

10. Musa R, Jamaiyah H, Azimah NM, Khairani O, Adam B. Cross-cultural Adaptation And Validation of the Malaysia Version of the Eating Disorder Examination Questionnaire (EDE-Q). Malaysian Journal of Psychiatry. 2008;17(2): 5563.

11. Kristine $H L$, Janice $H C$, Michele P. Eating Disorder Examination Questionnaire (EDE-Q): Norms for Undergraduate Women. Int J Eat Disord. 2008;41:273-276.

12. Oyvind R, Deborah LR, Bryan L. Norms for the Eating Disorder Examination Questionnaire among female university students in Norway. Nord J Psychiatry. 2010;64(6):428-432.

13. Fairburn CG. Eating Disorder Examination (Edition 16.0D) and Eating Disorder Examination Questionnaire (EDE-Q 6.0). In: Fairburn CG, editor. Cognitive therapy and eating disorders. New York Guildford Press. 2009; 265-313.

14. Mond JM, Hay PJ, Rodgers B, Owen C, Beumont PJV. Validity of the Eating Disorder Examination Questionnaire (EDE-Q) in screening for eating disorders in community samples. Behav Res Ther. 2004;42:551-567.

15. Mond JM, Hay PJ, Rodgers B, Owen C. Eating disorder examination questionnaire (EDE-Q): Norms for young adult women. Behav Res Ther. 2006;44:53-62.

16. Peláez-Fernández MA, Labrador FJ, Raich RM. Norms for the Spanish version of the Eating Disorders Examination Questionnaire (S-EDE-Q). Psicothema. 2013;25(1):107-114. 